\title{
A puzzle about Moorean metaphysics
}

\author{
Louis Doulas ${ }^{1}$
}

Published online: 14 March 2020

(C) Springer Nature B.V. 2020

\begin{abstract}
Some metaphysicians believe that existence debates are easily resolved by trivial inferences from Moorean premises. This paper considers how the introduction of negative Moorean facts-negative existentials that command Moorean certainty-complicates this picture. In particular, it shows how such facts, when combined with certain plausible metaontological principles, generate a puzzle that commits the proponents of this method to a contradiction.
\end{abstract}

Keywords Mooreanism $\cdot$ Common sense $\cdot$ Metaphysics $\cdot$ Metaontology $\cdot$ Ontology

Are there any negative Moorean facts? The positive Moorean facts are familiar enough: that I have hands, that there is time, motion, and a table before me. And many would agree that there are negative facts. But negative Moorean facts? It seems this question has gone unasked, yet an answer to it is presupposed by most philosophers: it's obviously not the case that there are some Fs. Familiar examples abound: there are no such things as the Tooth Fairy or Santa Claus, past and future times and objects, the fusion of your nose and the Eiffel Tower, or impossibiliaperhaps, there are no such things as non-existent objects at all! I think it's natural

Louis Doulas

ldoulas@uci.edu

1 Department of Philosophy, University of California, Irvine, 85 Humanities Instructional Building, Irvine, CA 92697-4555, USA 
and plausible, then, to assume that if there are any positive Moorean facts, there are negative Moorean facts too. ${ }^{1}$

In this paper, I'm interested in what follows once we take the idea of negative Moorean facts seriously. In particular, I'm interested in how negative Moorean facts make trouble for certain common sense approaches to ontology. Negative Moorean facts, when combined with some other plausible metaontological principles, seem to give rise to a puzzle which commits the Moorean metaphysician to a contradiction. Escape involves either giving up some negative Moorean fact for a positive one, or giving up some positive Moorean fact for a negative one. Either way, the cost is one's Mooreanism. Or, so I shall argue.

Here's the plan. In Sect. 1, I get clear on the principles that underwrite certain Moorean approaches to ontology. Drawing on these principles, I distinguish four specific Moorean approaches and, in Sect. 2, I argue that the Moorean should reject all but one. In Sect. 3, I present a puzzle that shows how the most plausible of these approaches leads to a contradiction. In Sect. 4, I consider possible resolutions to the puzzle and evaluate their plausibility without endorsing a specific solution. I conclude in Sect. 5 by attempting to diagnose what I take the real source of contention to be.

Some caveats before we begin. First, I'll take Moorean or neo-Moorean idioms in the vicinity-e.g., "Moorean facts," "Moorean truths," propositions that "command Moorean certainty" or are "obvious and undisputed," "commonsensical" or "of common sense," and propositions that correspond to our "ordinary, everyday beliefs" and "what we ordinary believe" —as all expressing (more or less) the same idea: that some propositions express truths we just shouldn't give up, even in the face of sophisticated philosophical arguments to the contrary. Here, I refer to them most frequently as "Moorean facts" and "Moorean truths."

Second, while I take the above gloss to capture the core epistemic commitments of Mooreanism (see also Sect. 1), it shouldn't be understood as a strict definition of Mooreanism. I won't offer such a definition here, nor will I provide any criteria for distinguishing Moorean facts from non-Moorean ones. Neither is necessary for my arguments to go through. Here and throughout, I'll simply assume that we know Moorean facts or truths when we see them. ${ }^{2}$

Finally, I'll be assuming a package of highly plausible logico-ontological principles: that quantification is "ontologically loaded," as well as the principle of existential generalization and the predication principle. This package should be familiar-it's orthodoxy-but, in Sect. 4, I'll consider whether these principles are

\footnotetext{
${ }^{1}$ Of course, some may doubt that Moorean facts-positive or negative-exist at all, or (if they do exist) find their epistemological legitimacy highly questionable. On Sider's (2013) view, for example, a theory's coherence with common sense counts for very little if it counts for anything at all. Furthermore, Conee (2001: 58) worries that the criteria some use to identify Moorean propositions may turn out to be entirely psychological. But we can put these worries aside here. In this paper, all I'm interested in is the conditional claim: supposing there are Moorean facts (and that such facts are evidential) are there negative Moorean facts in addition to the positive Moorean facts? And if so, what follows?

2 However, this isn't to say that no helpful characterization of common sense or Moorean truth exists. Compelling accounts are offered by both Kelly (2005, 2008) and Lycan (2001).
} 
our puzzle's real culprits and whether rejecting them is a plausible way of dissolving the puzzle. For now, however, I assume their cogency in my presentation of the puzzle.

\section{Mooreanism and trivialism: strong and weak}

Some metaphysicians offer a sweeping way to settle existence debates. Their recipe is simple. Suppose we're after an answer to (Q):

(Q): Do composite objects (like tables) exist?

An answer to (Q), so these metaphysicians say, is easy to come by. Given the evident fact that

(i) There are many tables before me.

it just follows that

(ii) There are tables.

The argument is valid, and its premise is clearly true. So, tables exist. As Jonathan Schaffer attests, "contemporary existence debates are trivial, in that the entities in question obviously do exist" (2009a: 357).

But why believe the premise(s) of easy ontological arguments like (i-ii) are true? The kind of metaphysician I'm interested in here says premises like (i) express something Moorean, they're "one of the many facts which even philosophers should not deny" (Armstrong 1978: 440-41), and that's reason enough for believing they're true. That is, they endorse what I'll call Moorean Ontological Arguments or MOAs for short. MOAs are just easy ontological arguments whose premise(s) express a Moorean fact. I'll call any metaphysician whose ontology is built from MOAs, a Moorean metaphysician or just a Moorean for short. ${ }^{3}$

Think of easy ontological arguments like (i-ii) as a map charting the ontological territory and Moorean principles as the reason for believing that the map is accurate. It's the support easy ontological arguments get from Moorean principles that make MOAs a philosophical force to be reckoned with. Consider, for example, a mereological nihilist's argument for the non-existence of tables. ${ }^{4}$ No matter how ingenious the argument, the Moorean instructs us not to budge. For denying that there are tables means giving up on a premise that deserves greater credence than any philosophical argument to the contrary. It means giving up on a premise we already know is true. If arguments serve as evidence, the Moorean has common

\footnotetext{
3 That ontology can be read off of certain claims of common sense, or that ontology should be constrained by common sense in some way has been endorsed or entertained (in some form or another) by Fine (2001: 2-3, 2009), Hirsch (2002, 2005), Kelly (2008), Korman (2019, forthcoming), Lycan (2001), Sattig (2015: 67-74), Schaffer (2009a, b: §4), and Thomasson (2007, 2015).

${ }^{4}$ I discuss the revisionist's strategy in more detail in Sect. 4. For a non-eliminative version of nihilism see Contessa (2014).
} 
sense as evidence on their side. Those with revisionary inclinations must deny known truths.

This dialectic is not unfamiliar. According to the Moorean, when it comes to believing a proposition of common sense versus a philosophical thesis that contradicts this proposition, the smart money is always on common sense:

No purely philosophical premise can ever (legitimately) have as strong a claim to our allegiance as can a humble common-sense proposition such as Moore's autobiographical ones. Science can correct common sense; metaphysics and philosophical "intuition" can only throw spitballs.

Lycan (2001: 41)

A simple point that Moore made in a number of papers is that our common sense convictions have more epistemic weight than any fancy philosophical arguments. Suppose you think you have an argument against the existence of tables. Maybe there is some mistake in the argument that you haven't seen. That's possible, isn't it? What is more likely, that there is a mistake in the argument or that there aren't any tables? Moore thought that any sane person who considers that question would soon realize that it is more reasonable to abandon the argument than to abandon tables.

Hirsch (2002: 104)

It is a very fundamental part of the Moorean corpus that there is motion. Things move. Perhaps we have still not, after two and a half thousand years, got to the full bottom of Zeno's brilliant arguments against the existence of motion... But certainly Zeno should not persuade us that things do not move. Neither should anybody else.

Armstrong (1999: 79)

[I]n this age of post-Moorean modesty, many of us are inclined to doubt that philosophy is in possession of arguments that might genuinely serve to undermine what we ordinarily believe. It may perhaps be conceded that the arguments of the skeptic appear to be utterly compelling; but the Mooreans among us will hold that the very plausibility of our ordinary beliefs is reason enough for supposing that there must be something wrong in the skeptic's arguments, even if we are unable to say what it is. In so far, then, as the pretensions of philosophy to provide a world-view rest upon its claims to be in possession of the epistemological high ground, those pretensions had better be given up.

Fine (2001: 2)

Here, without further ado, is a proof of the existence of numbers:

1. There are prime numbers.

2. Therefore there are numbers.

1 is a mathematical truism. It commands Moorean certainty, as being more credible than any philosopher's argument to the contrary. Any metaphysician 
who would deny it has ipso facto produced a reductio for her premises. And 2 follows immediately, by a standard adjective-drop inference. Thus numbers exist. End of story.

Schaffer (2009a: 357)

The norm of belief revision in operation here seems to be something like this (where $p$ is a proposition that expresses a Moorean fact): any philosophical argument that is at odds with $p$ is either outright flawed or its premise(s) should not be believed. So common sense is an indefeasible source of justification against philosophical arguments to the contrary. ${ }^{5}$ More precisely, then, the Moorean seems to be endorsing something like the following principle:

STRONG MOOREANISM

If $p$ is a Moorean fact and $q$ is the conclusion of a philosophical argument that contradicts $p$, and $S$ is deciding which proposition to believe, then $S$ should always believe $p$.

This formulation seems to gel best with the quoted material above, but also with the attitude of many other Moorean sympathizers. ${ }^{6}$ It also leaves open the possibility that scientific theses or arguments can be legitimate defeaters of Moorean truths, which the Moorean seems comfortable conceding. ${ }^{7}$

But one may wonder whether this characterization of Mooreanism is too strong. After all, for all the Moorean knows, there's a philosophical argument out there with revisionary implications whose premises all express Moorean facts. Is the Moorean really so foolish to deny such a possibility? Other self-professed Mooreans might think that it's at least epistemically possible that a philosophical argument (with all Moorean premises say) could come along and stir the pot. While this sort of Moorean may ultimately admit the unlikelihood of such a possibility, it's a possibility in their eyes no less. So it seems that Mooreanism comes in weaker and stronger blends. Perhaps such a Moorean would endorse:

WEAK MOOREANISM

If $p$ is a Moorean fact and $q$ is the conclusion of a philosophical argument that contradicts $p$, and $S$ is deciding which proposition to believe, then $S$ should almost always believe $p$ (otherwise $S$ should believe $q$ or suspend belief in $p$ ).

\footnotetext{
5 Not indefeasible simpliciter: science is capable of overturning Moorean common sense. See footnote 7.

6 See Armstrong (2004: 26-30), Gupta (2006: 178), Kelly (2005, 2008), and Lewis (1973: 88, 1996: 549).

7 So, in principle, premises like (i) can be overturned if (in a bizarre turn of events) the Physical Review were to come out claiming that the latest physics has debunked the existence of tables. Good work if you can get it, but what's left for philosophy? Why isn't philosophy gifted these debunking capabilities? The idea (so it goes) comes down to philosophy's inferior track record: science produces results and philosophy doesn't. Many Mooreans seem to converge on this point. For an interesting argument showing why philosophy can overturn Moorean common sense see Rinard (2013).
} 
Think of the proviso, "almost always," as picking out the specific instances in which the Moorean feels compelled to let a philosophical argument defeat a Moorean premise-whatever those cases may end up being and however the Moorean ends up deciding them.

In addition to STRONG MOOREANISM and WEAK MOOREANISM there's another important principle that seems to be endorsed by the Moorean-call it Trivialism: philosophical existence debates are highly trivial because they can be resolved by MOAs. By "resolved by MOAs" all I mean is that for any existence debate $d_{1}, \ldots$, $d_{n}$ the Moorean can provide an MOA such that the MOA answers a "Does $F$ exist?" question. Like our two Moorean principles above, Trivialism is also ambiguous, admitting of strong and weak readings:

STRONG TRIVIALISM

All existence debates are highly trivial because they can be resolved by MOAs.

WEAK TRIVIALISM

Some $^{8}$ existence debates are highly trivial because they can be resolved by MOAs.

What kinds of existence debates? If "all existence debates" is meant to refer, unrestrictedly, to any sort of "Are there $F$ s?" question (where " $F$ " can refer to just about anything, e.g., the number of socks in my drawer, North Korean weapons of mass destruction, etc.) then surely STRONG TRIVIALISM looks highly implausible. After all, whether there are any North Korean weapons of mass destruction is by no means trivially resolved, nor a question that MOAs are in the business of settling. I take it, then, that this isn't what proponents of either form of Trivialism have in mind by "existence debate." Instead, I take it that they mean something closer to the following: all philosophical existence debates. So, talk of "all" or "some" existence debates should be understood with this restriction in mind. ${ }^{9}$

\footnotetext{
8 "Some" has its typical reading as "at least one." But obviously if only one existence debate is resolved by an MOA, WEAK TRIVIALISM would be an extremely uninteresting principle. Perhaps, by "some" the Moorean means something closer to "most," as in exactly or more than half.

9 But even this restriction isn't restrictive enough. Though "philosophical existence debates" narrows the target of Trivialism somewhat, it still leaves much to be desired. If pressed further, here are some additional (vague and non-exhaustive) restrictions we might impose on our target: (a) debates that are determinately and distinctly philosophical, i.e., it's fairly clear that science-broadly construed-is incapable of settling them; (b) debates that only philosophers, analytic metaphysicians in particular, professionally engage in, i.e., debates that have been addressed in journals, presented at conferences, etc.; (c) debates that don't overlap with those that the general public might engage in, e.g., are there aliens, god(s), or souls?; and (d) debates that might strike the general public as having mostly obvious answers, e.g., are there tables?
} 
Thus, we are left with four possible Moorean metaontologies:

\begin{tabular}{ll} 
MM1 & MM2 \\
\hline STRONG MOOREANISM & STRONG MOOREANISM \\
STRONG TRIVIALISM & WEAK TRIVIALISM \\
MM3 & MM4 \\
\hline WEAK MOOREANISM & WEAK MOOREANISM \\
STRONG TRIVIALISM & WEAK TRIVIALISM
\end{tabular}

Which approach is the target of this paper? In the next section, I'll argue that no self-respecting Moorean should endorse the weak versions of these principles. This leaves us with what I believe to be the appropriate target of this paper, the Moorean approach deserving of serious philosophical consideration: MM1, or STRONG MOOREANISM with STRONG TRIVIALISM. Unfortunately, however, as I'll show in Sect. 3, MM1 entails a contradiction and is thus false.

Alternatively, this paper could be understood as presenting the Moorean with the following dilemma:

Either MM1 is contradictory, thus false, or

MM2 and MM3 and MM4 are consistent, but implausible.

Obviously this is bad news for the Moorean. If they can't find a way to make one of the above approaches work, Moorean metaontology looks like a nonstarter.

\section{Assessing the approaches}

Let's start with what I take to be the most implausible of the weak, MM3: wEAK MOOREANISM with STRONG TRIVIALISM. Together, these two principles yield the following: all and only philosophical existence debates can be resolved by Moorean principles; all other philosophical debates may (or may not be) resolved by such principles.

Yet, it's a bit strange-ad-hoc even - to maintain one's Mooreanism exclusively in the context of existence debates and not other philosophical debates. Why are existence debates more susceptible to Moorean reconciliation than other philosophical debates? Is there a special feature unique only to existence debates that somehow makes them more responsive to Moorean solutions than other philosophical debates? It's hard to take these questions seriously. Consider three distinct philosophical debates: Do properties exist? Are some moral truths self-evident? Do we have knowledge of the external world? Imagine only letting your Mooreanism settle the first debate (say, the existence of properties is entailed by certain Moorean facts like the following: there are properties that you and I share). But Mooreanism just as easily settles the remaining two debates. One might reason as follows: "murdering children for fun is wrong" is just obviously true; indeed, it's a Moorean 
fact. Therefore, some moral truths are self-evident. And: that I have hands is just obviously true; indeed it's a Moorean fact. So, if having hands entails that there is an external world, and I know that I have hands, then I have knowledge of the external world. Of course, there may be something independently objectionable about using Mooreanism to settle such debates, but the point is just that it'd be strange to restrict one's Mooreanism only to existence debates.

Moving on, we have MM2, STRONG MOOREANISM with WEAK TRIVIALISM, which entails the following: some existence debates can't be resolved by MOAs because there is no MOA-or no Moorean proposition(s) - that corresponds to/resolves those existence debates.

MM2 is certainly more plausible than the last. Intuitively, it at least seems as if MOAs are incapable of resolving some philosophical existence debates. Consider the debate over the existence of concrete possible worlds. Surely, this is a philosophical existence debate that no MOA can or will resolve. But I think this is a mistake. It's a mistake because it's unclear whether this debate is, at its core, philosophical or empirical. If it's the latter, then the Moorean will leave it up to science (perhaps cosmology) to settle it. But suppose it's really the former. Then I think common sense does rule it out: according to common sense, there are possibilities to be sure, but to analyze them as concrete possible worlds goes far beyond the jurisdiction of common sense. So, it turns out that common sense does rule out concrete possible worlds or else the question is in the hands of science and therefore outside the scope of Trivialism. Perhaps there are other philosophical existence debates that I'm overlooking that are more determinately philosophical that MOAs can't resolve. But given the relevant sense of "existence debate" ${ }^{10}$ it's hard to see how there isn't at least one MOA in the vicinity capable of resolving them.

Enter now the most plausible of the weak, MM4, WEAK MOOREANISM with WEAK TRIVIALISM, which says that some existence debates can't be resolved by MOAs and some Moorean facts can be overturned by radical philosophical arguments to the contrary (or rationally suspended until further notice).

Unlike the previous two approaches, MM4 has a lot going for it. But what's gained in plausibility is lost in credibility. The problem with MM4 is that it's simply not Moorean enough. Indeed, in principle, MM4 can accommodate a number of metaphysical positions that should, by the Moorean's lights, be deemed too radical to be taken seriously. MM4 permits one to be both a mereological nihilist and a believer in numbers, a modal realist and a believer in properties, a nominalist and a believer in tables. Yet, these ontologies are far from deserving the Moorean title.

So, the weak principles just seem too weak. This isn't to say that they're all lost causes. Indeed, I challenge the Moorean to mitigate some of the offenses enumerated here. Nevertheless, in light of the considerations above, I take the real target here to be MM1: STRONG MOOREANISM with STRONG TRIVIALISM.

Unlike its weak version, STRONG MOOREANISM better captures the epistemological commitments of the Moorean. It (rightly) prohibits any negotiation from taking place between the Moorean and other radical ontological/epistemological positions

${ }^{10}$ See footnote 9 for the relevant sense. 
(e.g., nihilism and skepticism). The modal force of "must" and "can" in the passages from Fine and Lycan above, ${ }^{11}$ for example, strongly imply that in no circumstance whatsoever should the Moorean concede to the revisionary. The Moorean doesn't negotiate with any kind of skeptic.

And STRONG TRIVIALISM, unlike its weak version, offers the Moorean a systematic way of doing ontology. This is because Trivialism is a metaontological principle, and metaontological principles are general guides to doing ontology. Trivialism, then, should tell the Moorean how to settle existence debates full-stop. For if only some existence debates are highly trivial, not only does Trivialism risk collapsing into a philosophically uninteresting thesis, but MOAs no longer look like a principled way of settling existence debates. ${ }^{12}$

So, though MM1 is seemingly more extreme than the other approaches, it has virtues the others lack: its commitments are clear and its approach is sufficiently principled. Moreover, it seems better supported by those who embrace Mooreanism.

\section{The puzzle}

Consider again argument (i-ii). We're supposed to believe that tables exist on the basis of the argument's premise. The premise is supposed to be obviously true-it commands Moorean certainty-so we should believe it. So, we should believe whatever this true premise entails: that there are tables.

But just as common sense corroborates many positive existential claims, so too, I think, it corroborates many negative existential claims. Common sense-as ontologically inclusive as it can be-excludes many things from reality. Paradigmatic examples include (inter alia) mythical and fictional things, past and future things/times, and impossible objects. Of course, this hasn't stopped philosophers from debating the existence of these things. My point is simply that, from the purview of common sense, it's obviously not the case that there exist some $F$ s. I take it, then, that there are certain negative Moorean facts of the form, "Fs don't exist" or "There are no Fs."

I turn now to the puzzle. To keep things clean and simple, I focus just on fictional things like the Tooth Fairy. ${ }^{13}$ And to keep things intuitive, I focus on singular propositions with the understanding that they can be transformed into general propositions. It will also be helpful to have in front of us the commitments of the Moorean approach in question:

\footnotetext{
11 Consider: "[T]here must be something wrong in the skeptic's arguments, even if we are unable to say what it is" (Fine 2001: 2) and "No purely philosophical premise can ever (legitimately) have as strong a claim to our allegiance as can a humble common-sense proposition" (Lycan 2001: 41, my emphasis).

12 In a slightly different context, Fairchild and Hawthorne (2018) argue against ontological conservatism on grounds that it's too particularist. I suspect something similar is going on with WEAK TRIVIALISM. Hence, perhaps, another reason to favor STRONG TRIVIALISM.

13 Technically, the Tooth Fairy is a creature of myth rather than one of fiction. But nothing important to my argument turns on this distinction.
} 


\section{MM1}

STRONG MOOREANISM

If $p$ is a Moorean fact and $q$ is the conclusion of a philosophical argument that contradicts $p$, and $S$ is deciding which proposition to believe, then $S$ should always believe $p$.

STRONG TRIVIALISM

All existence debates are highly trivial because they can be resolved by MOAs.

Now, just as much as common sense giveth, common sense taketh away. We granted this above. Common sense therefore licenses us to count the following claim as true, i.e., as one expressing a negative Moorean fact:

(r) The Tooth Fairy doesn't exist.

But consider now this positive Moorean fact:

(p) The Tooth Fairy is fictional.

From which it follows that:

(q) The Tooth Fairy exists.

What results is an inconsistent Moorean triad. $(q)$ is obviously in conflict with what we ordinarily believe: that the Tooth Fairy doesn't exist. What to do? Denying $(p)$ saves $(r)$ but at the cost of contradicting common sense. But saving $(p)$ means giving up $(r)$ which comes at the same cost. Do we kill one Moorean fact to save another? To dissolve the paradox, the Moorean must either reject $(r)$ or else deny $(p)$. From the standpoint of common sense, both options seem untenable. Slightly more formally: ${ }^{14}$

(1) STRONG MOOREANISM and STRONG TRIVIALISM are true. (assume for reductio)

(2) If STRONG MOOREANISM is true then the Tooth Fairy doesn't exist.

(3) If Strong moOREAnism is true then the Tooth Fairy is fictional.

(4) Therefore, the Tooth Fairy is fictional.

(from 1, 3)

(5) If STRONG TRIVIALism is true and the Tooth Fairy is fictional, then the Tooth Fairy exists.

(6) Therefore, the Tooth Fairy exists.

(from 4, 5)

(7) Therefore, the Tooth Fairy doesn't exist.

(8) Therefore, the Tooth Fairy exists and the Tooth Fairy doesn't exist. (from 6, 7)

(9) Therefore, STRONG MOOREANISM and STRONG TRIVIALISM are false.

(from 1,8 )

Thus, the conjunction of STRONG MOOREANISM and STRONG TRIVIALISM entails a contradiction.

With necessary alterations, the puzzle generalizes to other categories of entity: past and future things/times, impossible objects, and whatever else obviously

\footnotetext{
14 Thanks to an anonymous referee for suggesting I formalize the puzzle this way.
} 
doesn't exist. ${ }^{15}$ Consider, for example, past and future things/times. Our commonsensical conception of time and temporal experience support the belief that past and future things/times don't exist. ${ }^{16}$ Yet, it's a Moorean fact that some present objects stand in certain relations to past objects, e.g., I'm taller than Socrates. But to say this presupposes some past object (e.g., Socrates). But past objects don't exist! (Also a Moorean fact.) Of course, they did exist, but they don't now exist which is just to say they don't exist period. Likewise for future things/times. So, we have an inconsistent Moorean triad.

Impossible objects don't exist either. How could the round square exist? For it to exist there would have to be something that has the property of being both round and square which is, well, impossible. Nothing is or can be both round and square. So, the round square doesn't exist. That's a Moorean fact. Yet, it's also a Moorean fact that the round square is an impossible object. But this presupposes the existence of the round square! So, we have an inconsistent Moorean triad.

What does the puzzle show? Well, that if Moorean facts cut both ways-if there are both negative and positive Moorean facts - then, when combined with the aforementioned principles, they seem to force the Moorean to give up some of those facts (either some set of the negative facts or some set of the positive facts) to avoid contradiction. But no Moorean should have to do that. The Moorean shouldn't have to abandon any of the Moorean facts. What makes such facts Moorean is precisely their foundational and irrevocable status. ${ }^{17}$

There's also a second consequence of the puzzle. Consider again what MOAs are supposed to establish: that existence debates are trivial. They're trivial because they're easily resolved by MOAs. But the MOAs above seem to establish just the opposite: existence debates aren't trivial because they can't be easily resolved by the very MOAs that are supposed to easily resolve them.

So, the Moorean seems to have a puzzle on their hands.

\section{Possible resolutions}

I want to now consider some possible resolutions to the puzzle. Though I don't think any one approach decisively resolves the puzzle, I won't shy away from indicating which approaches I find most promising. I'll start first by discussing some possible epistemic solutions then transition to solutions that are more metaontological.

\footnotetext{
15 Maybe even non-existent objects themselves. Consider the sentence "The Tooth Fairy is non-existent" which some believe implies the existence of at least one non-existent object (e.g., the Tooth Fairy). But non-existent objects don't exist - they're not objects of any kind, they're nothing!

16 Saint Augustine concurs: "[I]t is abundantly clear that neither the future nor the past exist, and therefore it is not strictly correct to say that there are three times, past, present, and future" (Augustine 1961, Book XI §20: 269). Presentists do too. One of the cited upshots of the presentist view is that it coheres with common sense. (Of course, this is also what gets the presentist into trouble. If past things/times don't exist, it's not clear what could make sentences like "Caesar crossed the Rubicon" true. Likewise for sentences about the future.) See Zimmerman (2008) for further discussion.

17 Although, see footnote 5 .
} 


\subsection{Easy belief}

The Moorean might try sidestepping the puzzle by deferring to a principle like the following:

\section{EASY BELIEF}

If a premise $p$ of some MOA expresses a Moorean fact, but its conclusion $q$ doesn't, then $S$ should nevertheless believe $q$ on the basis of $p$ because $p$ expresses a Moorean fact.

Consider argument $(p-q)$ again. Its premise "The Tooth Fairy is fictional" expresses a Moorean fact while its conclusion "The Tooth Fairy exists" clashes with another Moorean fact "The Tooth Fairy doesn't exist." EASY BELIEF tells us that we should believe the conclusion of $(p-q)$ simply because its premise respects a Moorean fact.

But EASY BELIEF is implausible on two fronts. First, $(r)$-like $(p)$-expresses a Moorean fact. So respecting the Moorean facts can't be used as a condition for rejecting $(r)$ here since $(r)$ itself is a Moorean fact. Second, even if $(q)$ is a conclusion that is deduced by $S$ why should $S$ believe $(q)$ when $S$ believes more strongly in $(r)$ ? That is, if we are more certain of our belief in the proposition "The Tooth Fairy doesn't exist" why believe otherwise? If common sense counts in favor of truth and one is more certain of propositions which respect common sense than those that don't, it seems irrational to believe otherwise, especially when certainty about $(r)$ is stronger than mere belief in $(q)$.

I anticipate the following rejoinder: "But $(q)$ is the logical entailment of something we believe to be true, namely, $(p)$, and if we know $(p)$ to be true, and we're in a position to know what follows from $(p)$, then are we not justified in believing that $(q)$ is true?"

The problem with this line of reasoning is that we're both justified in believing that $(q)$ is true and also that $(r)$ is true. On the one hand, it's commonsensical to say that the Tooth Fairy is fictional. And since something isn't nothing then it seems we have evidence that something exists, namely, the Tooth Fairy. So, given that the former claim is supported by common sense, we're justified in believing it, hence we're justified in believing the entailment of that claim: fictional things like the Tooth Fairy exist. On the other hand, it's commonsensical to say that the Tooth Fairy doesn't exist. The Tooth Fairy is, after all, thought not to exist for good reason: it's made-up! And made-up things don't exist. Because our evidence for both claims is underdetermined we seem justified in believing either one. Therefore, believing $(q)$ on the grounds that it's entailed by $(p)$ (assuming our belief in $(p)$ is justified) isn't enough to decide the matter.

\subsection{Plausibility}

Perhaps the Moorean might retreat to a different sort of principle: 
PLAUSIBILITY

If at least one premise $p$ of some MOA is less plausible than the denial of its conclusion $q$, then $S$ shouldn't believe the premise of that MOA (otherwise $S$ should believe it). ${ }^{18}$

PLAUSIBILITY seems to do the trick for familiar MOAs like (i-ii). Is "There are many tables before me" less plausible than "Tables don't exist"? No. So, the Moorean should believe the premise of that MOA for the existence of tables.

Unfortunately, however, this move proves to be fruitless in the end as PLAUSIBILITY yields the same puzzling results. Consider again $(p-q)$ :

(p) The Tooth Fairy is fictional.

(q) Therefore, the Tooth Fairy exists.

With the updated decision procedure in place we can ask: Is $(p)$ less plausible than the negation of $(q)$ ? That is, is $(p)$ less plausible than $(r)$ ?

(r) The Tooth Fairy doesn't exist.

It's indeterminate given that $(p)$ seems equally as plausible as $(r)$. So PLAUSIBILITY gets the Moorean no closer to solving the puzzle.

So much for the epistemic route. On now to a different strategy: the metaontological route. If there is a solution to our puzzle at all, I suspect it resides here.

\subsection{Paraphrase}

One very natural response to the puzzle is to paraphrase. ${ }^{19}$ Quine taught us that when we're in an ontological bind we can eschew ontological commitment by locating an appropriate paraphrase. To avoid commitment to holes, for example, we might paraphrase "There are many holes in my sock" into "My sock is multiplyperforated." The Moorean might be tempted by a similar strategy. Perhaps there is a more natural translation of "The Tooth Fairy is fictional" that doesn't quantify over or entail the existence of the Tooth Fairy. Perhaps, then, the Moorean should only consider propositions that have first been vetted by paraphrase: if $p$ is a Moorean fact but has a paraphrase $p^{*}$ that isn't ontologically committing, then it shouldn't be used as a premise in an MOA. ${ }^{20}$

\footnotetext{
${ }^{18}$ If you find the plausibility relation too underspecified, feel free to substitute it with "certainty" or some other relevant epistemic notion.

19 The difference between reconciliatory and revisionary paraphrase matters here: the former aims to keep the original (unparaphrased) sentences true, while the latter renders them false. (See Keller (2010, 2015, 2016) for discussion of the differences.) The revisionary approach is likely to be of no interest to the Moorean since it would entail the falsity of some Moorean propositions. And while the reconciliatory approach looks initially promising, the Moorean might find that it fails in much the same way as other reconciliatory-inspired approaches, such as the fundamentalist approach considered in Sect. 4.5.

${ }^{20}$ Thanks to an anonymous referee for prompting me to reconsider this objection.
} 
But paraphrase seems antithetical to the Moorean approach to ontology in at least two ways. The Moorean deals in Moorean facts. These are facts that are meant to be unambiguous by design. Indeed, it's for this reason that they seem so compelling: they're true, obviously, as stated, no paraphrase necessary. ${ }^{21}$

Suppose, however, we were to grant the Moorean their paraphrases. If paraphrase is permissible, we might wonder what work MOAs are doing for the Moorean. Paraphrase enters the scene as a strategy for retaining one's preferred ontology. That is, before one paraphrases, one already has an ontology in mind that one intends the paraphrase to respect (hence the motivation to paraphrase away the existence of holes). Yet, the whole upshot of the Moorean approach is to use MOAs to settle existence debates. Mooreans employ MOAs to determine what exists. Paraphrase undermines this whole approach by forgoing MOAs altogether: with paraphrase, the Moorean picks and chooses their ontology ahead of time as opposed to letting ontology come to them by putting MOAs to work. It's not clear, then, how helpful paraphrase would be here to the Moorean.

\subsection{Pluralism}

Suppose instead that we were to make a distinction between what exists ${ }_{C}$ and what exists $_{A}$ where "exists $C$ " means something like "exists concretely" and where "exists ${ }_{A}$ " means something like "exists abstractly." The Moorean could then take (r) to mean:

\section{$(r)^{*}$ The Tooth Fairy doesn't exist ${ }_{C}$.}

And if the quantifiers in $(p-q)$ are taken to express "exists ${ }_{A}$ " then the contradiction disappears and the puzzle is resolved. Call this the ontological pluralist approach. ${ }^{22}$ Ontological pluralism says there are multiple ways for something to be. Some things exist concretely and other things exist abstractly, but make no mistake: both exist.

I think there are good, independent reasons for the Moorean not to adopt pluralism. ${ }^{23}$ Nevertheless, we can still ask: should the Moorean go pluralist for the simple reason that it resolves our puzzle? It's not clear they should. I assume what makes $(r)$ a Moorean fact is that it says the Tooth Fairy doesn't exist in any sense at all-not that it exists in some sense. Moreover, I don't think it's exactly commonsensical to hold that the Tooth Fairy, if it does exist, exists as an abstract object, outside of space (and perhaps time). If in order to resolve the puzzle the Moorean has to invoke strange, commonsensically dubious entities then the move to pluralism doesn't seem worth it.

\footnotetext{
21 See Schaffer (2009a: 357) for a similar line of reasoning.

22 See McDaniel (2017) and Turner (2010) for a defense of ontological pluralism.

23 See Merricks (2019) for critical discussion, much of which I'm sympathetic to.
} 


\subsection{Fundamentalism}

Could going "fundamental" escape the problem? Some metaphysicians make a distinction between fundamental and non-fundamental quantification. ${ }^{24}$ Call these metaphysicians fundamentalists. According to the fundamentalist, different senses of "there are/there exists" are invoked when making existential claims. For example, the quantifier we use when we're metaphysically serious can be dubbed the "fundamental quantifier" - it's the quantifier that "carves at the joints." When one denies the existence of tables, then, one is denying that fundamentally-speaking tables exist. But when one isn't doing metaphysics, and is out in the wild, furniture shopping (say), one's assertion that “There are many tables before me" doesn't entrap you in contradiction, for it doesn't commit you to tables. Here only a nonfundamental, ordinary sense of the quantifier is in use. And while what was said was literally and strictly true, it isn't ontologically deep or serious.

Why is fundamentalism relevant to the Moorean? Because having our ordinary common sense propositions come out true is one of the main motivations to go fundamental. Fundamentalists with revisionary inclinations (i.e., those who want to deny the existence of tables, numbers, and so on) want to hold on to the literal truth of common sense propositions that we (and they) all utter outside the seminar room. They would also like to be able to express their deep ontological commitments which seem to contradict these ordinary claims. To do both, they invoke the fundamental/non-fundamental distinction. Thus, the fundamentalist who doesn't like fictional things bloating their ontology might say "The Tooth Fairy exists" is true non-fundamentally-speaking (and therefore doesn't entail ontological commitment to fictional things) but false fundamentally-speaking, for fundamentallyspeaking, the Tooth Fairy doesn't exist. Puzzle solved.

The fundamentalist move is incredibly tempting. But the Moorean has good reason to be suspicious. For what good is the Moorean approach to ontology if it has nothing to do with ontology? If Moorean facts like "There are many tables before me" don't entail the existence of tables (in the fundamental sense) they seem useless to the Moorean who'd like to include such entities in their ontology-and include them on the basis of their entailment from claims that command Moorean certainty. The reason for believing in such entities is because they follow from such claims. The problem with fundamentalism, then, is that it seems to ask too much of the Moorean. For while it sidesteps the puzzle, it does so by radically reforming the scope and application of Moorean common sense. It then becomes quickly unclear what exactly the upshot of fundamentalism is supposed to be if the Moorean image it alleges to preserve is one the Moorean can't recognize. ${ }^{25}$

\footnotetext{
${ }^{24}$ See Cameron (2008, 2010), Dorr (2007), Fine (2001, 2009), and Sider (2009, 2011, 2013) for different but related strategies. See also van Inwagen (1990) for the locus of compatibilist-inspired strategies like these.

25 See also Korman (2015a, b, forthcoming) for critical discussion of the fundamentalist approach.
} 


\subsection{Neutralism}

Maybe a solution to our puzzle requires a departure from orthodoxy. That is, maybe rejecting the plausible logico-ontological principles we assumed from the outset (that quantification is "ontologically loaded," that the principle of existential generalization and the predication principle are sound) will set the Moorean metaphysician free. Suppose, then, we were to adopt a different view of quantification altogether-quantifier neutralism. ${ }^{26}$ Quantifier neutralism is just the view that quantification in natural and formal language is ontologically neutral, and thus not ontologically committing. The neutralist, then, rejects the package of logico-ontological principles we assumed from the start.

According to one sort of neutralist, quantificational expressions like "some," "there are," and " $\exists$ " don't mean there exists and therefore don't entail ontological commitment. Instead, existence is a predicate, " $E$," and ontological commitment is induced (or thwarted) by attaching that predicate to expressions in the following way: $\exists x(F x \wedge E x)$. In English: "There is something (e.g., the number 3) such that it is prime and it exists." Or if we think numbers don't exist: $\exists x(F x \wedge \sim E x)$. In English: "There is something (e.g., the number 3) such that it is prime and it doesn't exist." Thus, for the neutralist under consideration here, the domain of quantification includes both existent and non-existent things.

Neutralism has a seemingly elegant solution to the puzzle: "The Tooth Fairy is fictional" doesn't entail "The Tooth Fairy exists." All the former entails is that there is at least one non-existent fictional object in our domain of quantification. So, according to the neutralist, there is no inconsistent Moorean triad, for the inference is blocked: $(q)$ "The Tooth Fairy exists," is false and is in no way entailed by $(p)$ "The Tooth Fairy is fictional." Being non-existent doesn't preclude an object from having properties. Non-existent objects like the Tooth Fairy can have properties such as the property of being fictional.

Yet, neutralism seems to suffer a similar fate as fundamentalism. For I doubt the Moorean will like that (by the neutralist's lights) Moorean truths such as "There are many tables before me" don't entail the existence of tables. ${ }^{27}$

\footnotetext{
${ }^{26}$ The neutralist approach presented here is of the Meinongian sort and distinguishes being from existence in addition to holding that non-existent objects have genuine properties. But neutralism and Meinongianism aren't a package deal. For a defense of anti-Meinongian neutralism see Azzouni (1994, 2004, 2017). See also Fine (2009) for a nuanced view in the vicinity. For more classic Meinongian-inspired views see Crane (2012, 2013), Finn (2017), Priest (2005, 2008), and Routley (1980, 1982).

27 Suppose, however, a compromise is reached. Maybe according to the neutralist "tables exist" is true not because it was deduced from any MOA but because tables just exist! That is, instead of inferring the conclusion "tables exist" from a Moorean premise "There are many tables before me" the neutralist can simply insist that "tables exist" is true because it just expresses a brute Moorean fact.

I think this strategy will only take the neutralist so far. For consider how such a neutralist might arrive at this truth. Plausibly, they might do so on the basis of having some perceptual experience: they see that this table exists in front of them. But consider now other sorts of entities like properties and numbers. Here, such a neutralist couldn't help themselves to a similar response. One doesn't see that properties exist. One deduces their existence from other, more basic (Moorean) facts, e.g., this apple is red and that car is red, so there is a property-redness - that both objects share. So, while "properties exist" might very well be a Moorean truth of its own, it's one that is entailed by some other more basic set of Moorean truths. Yet, the neutralist can't grant this since such inferences are blocked by their alleged ontological neutrality.
} 


\subsection{No negative Moorean facts}

If the puzzle only gets started if negative Moorean facts are countenanced (and $(r)$ "The Tooth Fairy doesn't exist" is a paradigmatic instance of one), then one might be inclined to do away with negative Moorean facts completely. Maybe there aren't any such facts at all. Maybe negative Moorean facts are too philosophically controversial to be considered genuine Moorean facts. The positive Moorean facts are just less divisive. Then, the puzzle would fail since one could just deny $(r) .^{28}$

This move, however, strikes me as desperate. Mooreans don't need to agree on all the Moorean facts, be they positive or negative ones. Disputes, "in-house" disputes especially, come with the territory. So, "being controversial," shouldn't preclude negative existentials from being ascribed Moorean status. Moreover, failure to countenance negative Moorean facts seems to lead to a failure to explain the great efforts philosophers have gone to to keep negative existentials true. The sophisticated logical acrobatics of Russell and Quine were seemingly performed out of respect for the negative Moorean facts: that Pegasus and the present King of France really don't exist in any sense at all. No ancient puzzle was ever going to stop them from believing otherwise. Perhaps, this is why any "solution" that turns on denying true negative existentials feels so unsatisfying. For it fails to accommodate a desideratum that any even remotely plausible solution must accommodate: that some things don't exist.

The Moorean seems backed into a corner. With no way to override the puzzle, MOAs look like an inconsistent and ineffectual way of settling existence debates.

\section{Concluding remarks}

Inconsistent beliefs aren't anything new. When we discover an inconsistency in our belief system, we update it accordingly, shoring up the unwanted inconsistency by deciding to endorse some propositions and rejecting others. In the cases above, however, it's unclear how exactly we might do this: MM1 seems to allow no wiggle room. What, then, to make of our puzzle? Assuming that the other three approaches are off the table, either Mooreanism or Trivialism—or both—must go!

The dilemma, recall, is this: the Moorean can't consistently maintain that $(r)$ "The Tooth Fairy doesn't exist" and $(p)$ "The Tooth Fairy is fictional" are true. For the latter, positive Moorean fact entails the existence of the Tooth Fairy, which contradicts the former, negative Moorean fact. In order to slip out of the contradiction, then, it looks like the Moorean has to give one fact up for the other. But Moorean facts are irrevocable (at least no philosophical argument is capable of overturning them). So, giving up either fact isn't an option for the Moorean.

\footnotetext{
${ }^{28}$ Of course, to deny ( $r$ ) the Moorean needn't do away with negative Moorean facts completely. For they might agree that negative Moorean facts exist but disagree that $(r)$ is one of them. One can also go in the other direction and deny that $(p)$ "The Tooth Fairy is fictional" is a Moorean fact. But I think this is just as implausible as denying that $(r)$ is a Moorean fact.
} 
Perhaps, then, some would like to keep Trivialism and give up Mooreanism: easy ontological arguments like (i-ii) get by just fine without Moorean principles.

But then we might wonder why the premise(s) of such arguments are true. Why believe them? What's doing the justificatory work? If it isn't Mooreanism, or if it's something weaker than Mooreanism, proponents of easy ontological arguments should be open to potentially revising their ontological beliefs in the face of radical but compelling philosophical arguments to the contrary. (Recall that proponents of MOAs are unwilling to concede this since it would mean giving up on some Moorean truths.) Yet, I assume that those interested in Trivialism are interested in easy ontological arguments because they seem like a compelling way of settling existence debates. But if revising one's ontological beliefs in the face of such arguments is a real option, why think such debates are "trivial" or "easily resolved" in the first place?

Maybe others would be tempted to give up Trivialism and keep Mooreanism. Maybe all existence debates are highly non-trivial. Or maybe existence debates are all trivial in some other way than what Trivialism suggests. ${ }^{29}$ Whatever the case, the proponent of such a view has modest aspirations: Mooreanism settles some philosophical debates to be sure, but which ones? I take it that those attracted to this approach recommend patience: answers are to be discovered piecemeal, on a caseto-case basis.

One last way forward is to embrace some general form of anti-Mooreanism and anti-Trivialism. Anti-Mooreanism because common sense doesn't count for much; anti-Trivialism because existence debates are highly non-trivial.

How would an approach like this one play out? Well, everyone can agree that common sense is an acceptable starting point. (What else is one supposed to lean on at the beginning of inquiry?) But instead of letting common sense stubbornly dictate what, in the final analysis, there is and what there isn't, it should be renegotiated when new evidence comes along. For instance, J.R.G. Williams suggests that the real Moorean challenge ought to focus not on the relative justification of one's beliefs but when and under what conditions it is rational to change these beliefs. ${ }^{30}$ With the right sort of philosophical argument, then, it should be permissible to give up our belief in certain Moorean propositions. ${ }^{31,32}$ Of course, much turns on fleshing out the "what" and "when" of rational belief change. For if the conditions are too

\footnotetext{
${ }^{29}$ Korman (forthcoming) seems to endorse a view like this one.

30 Although note that Williams goes on to develop a compatibilist strategy similar in spirit to the fundamentalist. See Williams (2012: 167).

31 It's easy to see how some form of anti-Trivialism follows: if we're justified in rejecting the premise(s) of MOAs like (i-ii), settling existence debates by MOAs looks futile.

32 It's an interesting question as to how "anti-Moorean" the proposal sketched here really is and whether it could be accommodated by something like WEAK MOOREANISM. My response to the former is that it's anti-Moorean in the sense that common sense doesn't count for much: it only guides initial inquiry and can be overturned by compelling philosophical arguments to the contrary. I take it that no Moorean would be happy with this outcome. As for whether this "anti-Mooreanism" coheres with WEAK MOOREANISM: it doesn't insofar as proponents of WEAK MOOREANISM only believe it's every blue moon (if ever actually the case) that common sense can be philosophically overturned. The anti-Mooreanism here says that this happens more frequently than proponents of WEAK MOOREANISM are comfortable conceding.
} 
stringent, we could slide back into Mooreanism; but if the conditions are too permissive, we could end up with something deeply unprincipled, or worse, incoherent.

Let's zoom out. What I think our puzzle and possible solutions point to are two different ways of conceiving of Moorean knowledge: is Moorean knowledge "metaphysically transparent" or is it "metaphysically opaque"? Consider the kind of Moorean under scrutiny here. The reason such a Moorean might find compatibilist strategies like paraphrase or fundamentalism unconvincing is because they believe Moorean knowledge is transparent: knowledge of what there is and what things are like is fairly easy to obtain. Knowing that there are many tables before me entails knowing that tables_-composite objects-really exist. So, if you know the Moorean facts, then you know what really exists.

But if Moorean knowledge is opaque, one can't just know that composite objects really exist merely on the basis of knowing the Moorean facts (e.g., that there are many tables before me); for knowing the Moorean facts doesn't necessarily entail knowing what's metaphysically or ontologically the case. The fact that there are many tables before me is compatible with a variety of metaphysical worldviews, including the nihilists' which insists that there are no tables at all, just simples arranged tablewise. This is the compatibilist gambit: one gets to hold on to common sense and radical ontology but only on the condition that Moorean knowledge is metaphysically opaque.

If you're sympathetic to the opacity of Moorean knowledge, then it seems the puzzle disappears: all the positive Moorean facts are true (non-fundamentallyspeaking), while all the negative Moorean facts are true (fundamentally-speaking). This in itself invites some questions (why, for example, are only negative Moorean facts true, fundamentally-speaking) and those sympathetic to the transparency of Moorean knowledge can always push back and complain that compatibilist strategies like fundamentalism aren't commonsensical or Moorean enough; that the motivation to save common sense is undercut by what the compatibilist claims common sense is compatible with: that there really are no tables at all. Yet, if one is sympathetic to the transparency of Moorean knowledge, then it looks like one is saddled with the puzzle. But our puzzle seems to cry out for a seachange: philosophical arguments need to be capable of undermining Moorean common sense or else they land the Moorean in paradox.

Acknowledgements For comments and encouragement on a very early (and by now unrecognizable!) draft, thanks to Simon Hewitt, Matthias Jenny, and Marcello Sachs. For many helpful comments and conversations on various drafts in between, I'm grateful to Sayid Bnefsi, Andrew Brenner, Lia Curtis Fine, Taylor Dunn, Simon Evnine, Mark Fiocco, Daniel Friedman, Michelle Kim Gardner, Kellan Head, Shane Henckel, Eli Hirsch, Dan Korman, Andre LeBrun, Beri Marušić, Genae Matthews, Giulia Napolitano, Kyle O'Dwyer, Oscar Piedrahita, Nick Smith, Evan Sommers, Amie Thomasson, Jessica Wei, Evan Welchance, Douglas Yetman, and audiences at The 3rd Johns Hopkins University Graduate Philosophy Conference. Special thanks to an anonymous referee at Philosophical Studies whose invaluable and incisive comments greatly improved this paper.

\section{References}

Armstrong, D. M. (1978). Universals and scientific realism. Cambridge: Cambridge University Press. Armstrong, D. M. (1999). A naturalist program: Epistemology and ontology. Proceedings and Addresses of the American Philosophical Association, 73, 77-89. 
Armstrong, D. M. (2004). Truth and truthmakers. Cambridge: Cambridge University Press.

Augustine. (1961). Confessions (R. S. Pine-Coffin, Trans.). Harmondsworth: Penguin.

Azzouni, J. (1994). Metaphysical myths, mathematical practice: The ontology and epistemology of the exact sciences. Cambridge: Cambridge University Press.

Azzouni, J. (2004). Deflating existential consequence. Oxford: Oxford University Press.

Azzouni, J. (2017). Ontology without borders. Oxford: Oxford University Press.

Cameron, R. P. (2008). Truthmakers and ontological commitment: Or, how to deal with complex objects and mathematical ontology without getting into trouble. Philosophical Studies, 140, 1-18.

Cameron, R. P. (2010). Quantification, naturalness, and ontology. In A. Hazlett (Ed.), New waves in metaphysics (pp. 8-26). Houndmills: Palgrave Macmillan.

Conee, E. (2001). Comments on Bill Lycan's Moore against the new skeptics. Philosophical Studies, 103, 55-59.

Contessa, G. (2014). One's a crowd: Mereological nihilism without ordinary-object eliminativism. Analytic Philosophy, 55, 99-221.

Crane, T. (2012). Existence and quantification reconsidered. In T. Tahko (Ed.), Aristotelian metaphysics (pp. 44-65). Cambridge: Cambridge University Press.

Crane, T. (2013). The objects of thought. Oxford: Oxford University Press.

Dorr, C. (2007). There are no abstract objects. In J. Hawthorne, T. Sider, \& D. W. Zimmerman (Eds.), Contemporary debates in metaphysics (pp. 32-63). Malden, MA: Blackwell.

Fairchild, M., \& Hawthorne, J. (2018). Against conservatism in metaphysics. Royal Institute of Philosophy Supplement, 82, 45-75.

Fine, K. (2001). The question of realism. Philosopher's Imprint, 1, 1-30.

Fine, K. (2009). The question of ontology. In D. Chalmers, D. Manley, \& R. Wasserman (Eds.), Metametaphysics: New essays on the foundations of ontology (pp. 157-177). Oxford: Oxford University Press.

Finn, S. (2017). The role of existential quantification in scientific realism. Philosophy, 92, 351-367.

Gupta, A. (2006). Empiricism and experience. Oxford: Oxford University Press.

Hirsch, E. (2002). Against revisionary ontology. Philosophical Topics, 30, 103-127.

Hirsch, E. (2005). Physical-object ontology, verbal disputes, and common sense. Philosophy and Phenomenological Research, 70, 67-97.

Keller, J. A. (2010). Telling the whole truth: The role of paraphrase in philosophical inquiry. Ph.D. Dissertation, University of Notre Dame.

Keller, J. A. (2015). Paraphrase, semantics, and ontology. In K. Bennett \& D. Zimmerman (Eds.), Oxford studies in metaphysics (Vol. 9, pp. 89-128). Oxford: Oxford University Press.

Keller, J. A. (2016). Paraphrase and the symmetry objection. Australasian Journal of Philosophy, 95, $365-378$.

Kelly, T. (2005). Moorean facts and belief revision or can the skeptic win? Philosophical Perspectives, 19, 179-209.

Kelly, T. (2008). Common sense as evidence: Against revisionary ontology and skepticism. In P. French \& H. Wettstein (Eds.), Midwest studies in philosophy: Truth and its deformities (Vol. 32, pp. 53-78). Oxford: Blackwell.

Korman, D. Z. (2015a). Fundamental quantification and the language of the ontology room. Nô̂s, 29, 298-321.

Korman, D. Z. (2015b). Objects: Nothing out of the ordinary. Oxford: Oxford University Press.

Korman, D. Z. (2019). Easy ontology without deflationary metaontology. Philosophical and Phenomenological Research, 99, 236-243.

Korman, D. Z. (forthcoming). Why care about what there is? In J. Cumpa (Ed.), The Question of Ontology. Oxford University Press.

Lewis, D. (1973). Counterfactuals. Cambridge, MA: Harvard University Press.

Lewis, D. (1996). Elusive knowledge. Australasian Journal of Philosophy, 74, 549-567.

Lycan, W. (2001). Moore against the new skeptics. Philosophical Studies, 103, 35-53.

McDaniel, K. (2017). The fragmentation of being. Oxford: Oxford University Press.

Merricks, T. (2019). The only way to be. Noûs, 53, 593-612.

Priest, G. (2005). Towards non-being. Oxford: Clarendon Press.

Priest, G. (2008). The closing of the mind: How the particular quantifier became existentially loaded behind our backs. The Review of Symbolic Logic, 1, 42-55.

Rinard, S. (2013). Why philosophy can overturn common sense. In T. Szabó Gendler \& J. Hawthorne (Eds.), Oxford studies in epistemology (Vol. 4, pp. 185-213). Oxford: Oxford University Press. 
Routley, R. (1980). Exploring Meinong's jungle and beyond: An investigation of noneism and the theory of items., Philosophy Department Monograph 3 Canberra: Research School of Social Sciences, Australian National University.

Routley, R. (1982). On what there is not. Philosophy and Phenomenological Research, 43, 151-177.

Sattig, T. (2015). The double lives of objects: An essay in the metaphysics of the ordinary world. Oxford: Oxford University Press.

Schaffer, J. (2009a). On what grounds what. In D. Chalmers, D. Manley, \& R. Wasserman (Eds.), Metametaphysics: New essays on the foundations of ontology (pp. 347-383). Oxford: Oxford University Press.

Schaffer, J. (2009b). The deflationary metaontology of Thomasson's Ordinary Objects. Philosophical Books, 50, 142-157.

Sider, T. (2009). Ontological realism. In D. Chalmers, D. Manley, \& R. Wasserman (Eds.), Metametaphysics: New essays on the foundations of ontology (pp. 384-423). Oxford: Oxford University Press.

Sider, T. (2011). Writing the book of the world. Oxford: Oxford University Press.

Sider, T. (2013). Against parthood. In K. Bennett \& D. W. Zimmerman (Eds.), Oxford studies in metaphysics (Vol. 8, pp. 237-293). Oxford: Oxford University Press.

Thomasson, A. L. (2007). Ordinary objects. New York: Oxford University Press.

Thomasson, A. L. (2015). Ontology made easy. Oxford: Oxford University Press.

Turner, J. (2010). Ontological pluralism. Journal of Philosophy, 107, 5-34.

Van Inwagen, P. (1990). Material beings. Ithaca, NY: Cornell University Press.

Williams, J. R. G. (2012). Requirements on reality. In F. Correia \& B. Schnieder (Eds.), Metaphysical grounding: Understanding the structure of reality (pp. 165-185). Cambridge: Cambridge University Press.

Zimmerman, D. (2008). The privileged present: Defending an 'A-Theory' of time. In T. Sider, J. Hawthorne, \& D. W. Zimmerman (Eds.), Contemporary debates in metaphysics (pp. 211-225). Malden: Blackwell Publishing.

Publisher's Note Springer Nature remains neutral with regard to jurisdictional claims in published maps and institutional affiliations. 